Review

\title{
Long Non-Coding RNAs Dysregulation and Function in Glioblastoma Stem Cells
}

\author{
Xiaoqin Zhang, Karrie Meiyee Kiang, Grace Pingde Zhang and Gilberto Kakit Leung * \\ Department of Surgery, Li Ka Shing Faculty of Medicine, The University of Hong Kong, \\ Hong Kong, China; E-Mails: zhxq@ connect.hku.hk (X.Z.); kkarrie@ connect.hku.hk (K.M.K.); \\ pingder@hku.hk (G.P.Z.) \\ * Author to whom correspondence should be addressed; E-Mail: gilberto@hku.hk; \\ Tel.: +852-2255-3368; Fax: +852-2818-4350.
}

Academic Editor: George A. Calin

Received: 9 April 2015/ Accepted: 28 May 2015/ Published: 3 June 2015

\begin{abstract}
Glioblastoma multiforme (GBM), the most common form of primary brain tumor, is highly resistant to current treatment paradigms and has a high rate of recurrence. Recent advances in the field of tumor-initiating cells suggest that glioblastoma stem cells (GSCs) may be responsible for GBM's rapid progression, treatment resistance, tumor recurrence and ultimately poor clinical prognosis. Understanding the biologically significant pathways that mediate GSC-specific characteristics offers promises in the development of novel biomarkers and therapeutics. Long non-coding RNAs (lncRNAs) have been increasingly implicated in the regulation of cancer cell biological behavior through various mechanisms. Initial studies strongly suggested that lncRNA expressions are highly dysregulated in GSCs and may play important roles in determining malignant phenotypes in GBM. Here, we review available evidence on aberrantly expressed lncRNAs identified by high throughput microarray profiling studies in GSCs. We also explore the potential functional pathways by analyzing their interactive proteins and miRNAs, with a view to shed lights on how this novel class of molecular candidates may mediate GSC maintenance and differentiation.
\end{abstract}

Keywords: glioblastoma stem cell; lncRNA; transcription factor; miRNA; lncRNA-protein interaction; lncRNA-miRNA interaction; signal pathway 


\section{Introduction}

An important progress in cancer biology has been the identification of a key subpopulation of tumor cells with stem cell properties, now commonly referred to as cancer stem cells (CSCs) [1,2]. The latter make up only a small fraction of the tumor cell mass, but are thought to be able to self-renew and re-generate the parent tumor [1-4]. Glioblastoma multiforme (GBM), the most common and deadly malignant primary brain tumor, was among the first solid tumors in which the existence of CSCs was experimentally demonstrated about a decade ago [5-7]. Currently, glioblastoma stem cells (GSCs) have been extensively validated in various preclinical models and characterized as the tumor-initiating cells of GBM, as well as the potential reason for the tumor's innate radio-chemo resistance [8-14]. These findings provided an impetus for furthering our understanding of the cellular and molecular mechanisms of tumor maintenance and recurrence in GBM.

Long non-coding RNAs (lncRNAs), which are by definition transcripts with lengths greater than 200 nucleotides and without protein-coding function, have been proposed as key regulators of diverse biological processes including cell pluripotency and tumorigenesis [15-18]. They are aberrantly expressed in a variety of diseases, and may mechanistically interact with key proteins or RNAs to execute their biological functions at various levels $[16,18,19]$. Increasing evidence shows that abnormal expression of lncRNAs may alter basic cellular biological processes and contribute to the malignant phenotypes in GBM [20-24]. Moreover, differential expression of specific lncRNAs may also correlate with the tumorigenic properties of GSCs [25].

In this review, we summarize currently available evidence regarding the potential associations between lncRNAs and GSCs. First, we review the current knowledge about the definitions, characteristics and biomarkers of GSCs. Second, we provide a comprehensive summary of known lncRNA dysregulations in GSCs by screening existing microarray gene expression data. Finally, we discuss the potential functions and mechanisms of these lncRNAs in GSC maintenance and differentiation by analyzing the formers' interactive transcription factors (TFs), miRNAs as well as RNA binding proteins (RBPs).

\section{GSCs-Definitions, Characteristics and Biomarkers}

Despite continued efforts, there is as yet no consensus within the scientific community on how to define CSCs and thus GSCs. According to the American Association of Cancer Research (AACR) workshop, CSCs are a subpopulation of cells that have the capacities for self-renewal and differentiation into heterogeneous subpopulations of cancer cells that comprise the tumor [26]. To be identified as GSCs, therefore, glioblastoma cells must possess the ability of sustainable neurosphere formation in culture and tumor generation in vivo (self-renewal), as well as the ability to differentiate into multiple neural lineages that recapitulate the initiate tumor pathology (multiple differentiation) [27,28]. From a clinical point of view, GSCs are thought of as the small fraction of malignant cells that may survive conventional chemo-and radiotherapy, and regenerate recurrent tumors [12,29,30] (Figure 1).

While there has been considerable interest in studying CSCs derived from GBM tissues, isolating this sparse population of cells with high yield and viability from tumor bulks has been a challenge. These cells have been isolated in serum-lacking media containing growth factors, and would aggregate into 
spheres in suspension [5-7]. The main advantage of the serum-lacking culture method is the greater preservation of native phenotypes and genotypes, which are less well preserved in cells cultured in serum-containing medium because of the accumulation of aberrations over repeated passaging [31]. In contrast to the hyper-proliferative and hyper-angiogenic phenotypes of glioblastoma tumors, GSCs possess neuroectodermal properties, and express genes associated with neural stem cells, radial glial cells and neural crest cells, while portraying also a migratory, quiescent and undifferentiated phenotype [32]. Thus, cell-cycle-targeted radio-chemotherapy, which aims to kill fast-growing tumor cells, would not completely eliminate GBM tumors [32].

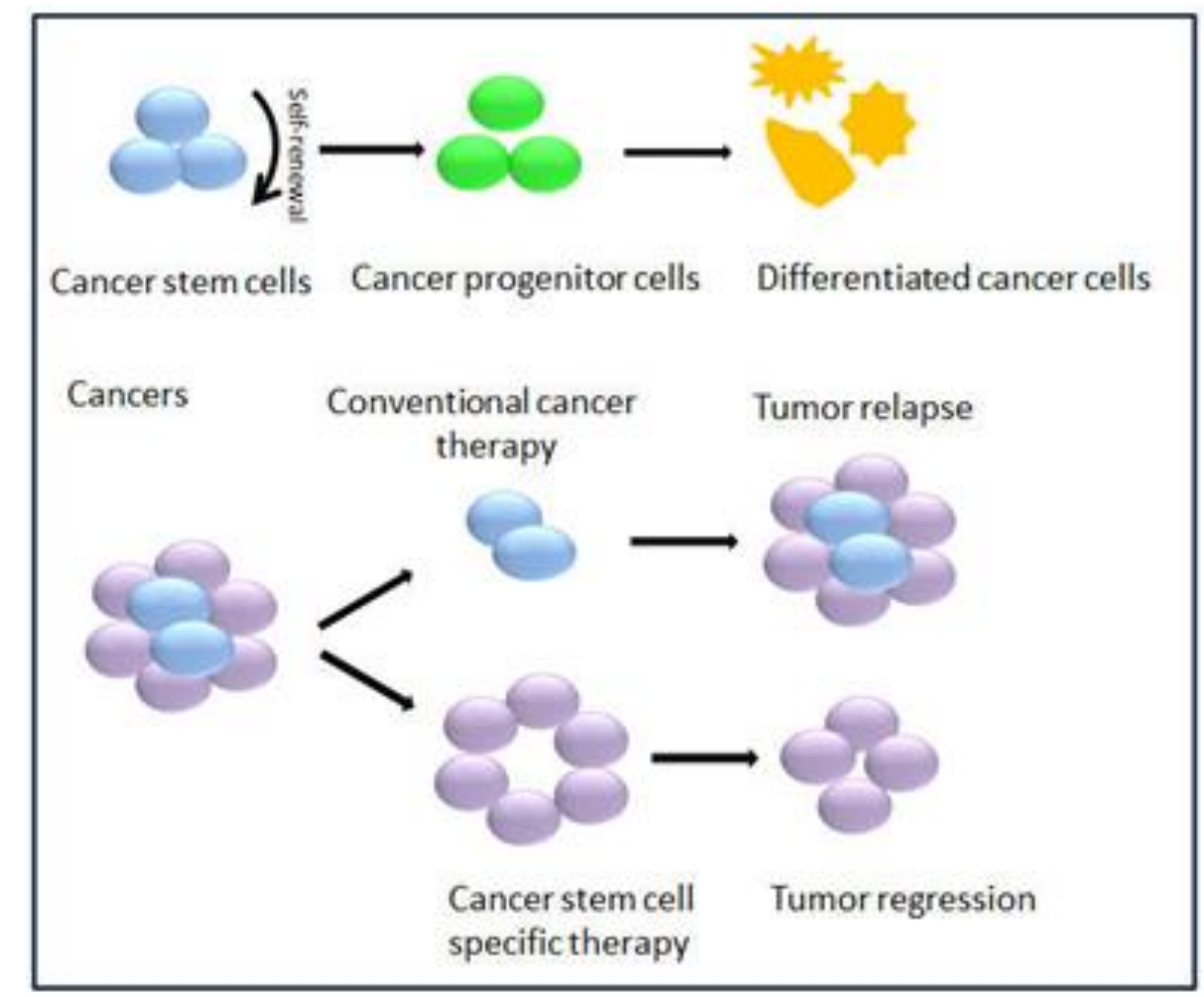

Figure 1. Cancer stem cell theory.

GSCs have biomarkers that are distinct from those found in differentiated tumor cells, and the isolation of GSCs based on surface markers is now feasible [33]. Currently, a subset of identifiable surface markers, summarized in several comprehensive reviews [14,28,34,35], has been used to isolate and characterize GSCs even though their specificities remain controversial. These include CD133, A2B5, Musashi-1 and Nestin. Amongst these, CD133, also referred to prominin-1, is the most widely studied and employed marker for GSCs. CD133 is a trans-membrane protein with no clearly-defined function [36,37]. Multiple independent studies found that CD133 + GBM cells fulfilled the definition of GSCs in that they had higher colony formation efficiency, multilineage differentiation capacity, and an increased ability to form tumors in serially transplantable xenografts when compared to CD133 - GBM cells [5,6,30,32,38,39]. However, subsequent studies revealed that CD133 did not consistently distinguish GSCs from non-GSCs, and CD133- cells may also be tumorigenic when xenografted in vivo [40,41]. These discrepancies illustrate the potential heterogeneity of GSCs as well as the necessity to employ combined markers or methods (such as functional identification) in enriching and validating GSC populations. 


\section{LncRNAs Dysregulated in GSCs}

The distinct growth behaviors and characteristics of GSCs mean that it is intellectually attractive and clinically relevant to identify the underlying molecular characteristics, which may provide new insights into the elimination of this subpopulation of cells and provide curative strategies. Previous genome-wide profiling studies have identified aberrantly expressed protein-coding genes and miRNA genes associated with GSCs [39-42]. In contrast, dysregulation of lncRNAs in GSCs at individual gene levels have not been reported until recently; the global and comprehensive lncRNA transcriptome features in GSCs remain largely unknown. Our previous studies and several other independent studies showed that lncRNA profiling could actually be achieved by mining the existing microarray gene data, such as the Affymetrix microarray datasets [43-46]. Based on this approach, the dysregulated lncRNAs associated with GSC properties are comprehensively screened and summarized in this present review. The published GSC microarray gene expression study (on Affymetrix HG U133 Plus 2.0 platform) used for lncRNA mining here, as well as the dysregulated lncRNAs identified from them, are summarized in Table 1.

Table 1. Published GSC profiling studies as well as the dysregulated lncRNAs identified.

\begin{tabular}{|c|c|c|c|c|c|}
\hline Authors ${ }^{1}$ & Year & Samples & $\begin{array}{c}\text { No. of } \\
\text { Up-regulated LncRNAs }(\geq 2.0 \text { fold })^{2}\end{array}$ & $\begin{array}{l}\text { No. of } \\
\text { Down-regulated LncRNAs }(\geq 2.0 \text { fold })^{2}\end{array}$ & Ref. \\
\hline \multicolumn{6}{|c|}{ Dysregulated LncRNAs between GSCs and Differentiated GBM Cells Comparison } \\
\hline Araki et al. & 2013 & $\begin{array}{l}\text { GSC (sphere) vs. } \\
\text { differentiated } \\
\text { GBM cells }\end{array}$ & $\begin{array}{l}\text { 6: LOC100127888, H19, } \\
\text { RP11-112J3.16, et al. }\end{array}$ & $\begin{array}{l}\text { 28: DLX6-AS, LOC643763, } \\
\text { FLJ39609, et al. }\end{array}$ & [47] \\
\hline Aldaz et al. & 2013 & $\begin{array}{l}\text { GSC (sphere) vs. } \\
\text { differentiated } \\
\text { GBM cells }\end{array}$ & $\begin{array}{l}\text { 28: H19, MIAT, LOC150622, } \\
\text { LOC100127888, XIST, } \\
\text { RP11-112J3.16, et al. }\end{array}$ & $\begin{array}{l}\text { 11: RP11-346D6.6, C6orf155, HCG4, } \\
\text { FLJ39609, et al. }\end{array}$ & [42] \\
\hline \multicolumn{6}{|c|}{ Dysregulated LncRNAs between GSCs with Different Subtypes } \\
\hline Beier et al. & 2007 & $\begin{array}{l}\text { CD133 + GSCs } \\
\text { vs. CD133- } \\
\text { GSCs }\end{array}$ & $\begin{array}{l}\text { 38: XIST, H19, HOTAIR, LOC100192378, } \\
\text { AC006213.1, MIAT, et al. }\end{array}$ & $\begin{array}{l}\text { 34: CTC-231O11.1, RP11-745C15.2, } \\
\text { LOC100130776, C14orf139, et al. }\end{array}$ & [40] \\
\hline Gunther et al. & 2008 & $\begin{array}{l}\text { CD133+ GSCs } v s \\
\text { CD133- GSCs }\end{array}$ & $\begin{array}{l}\text { 51: H19, RP11-331K15.1, RP11-547I7.2, } \\
\text { LOC100192378, MIAT, HOTAIR, et al. }\end{array}$ & $\begin{array}{l}\text { 10: C14orf139, DLX6-AS, MIR155HG, } \\
\text { LOC100130776, et al. }\end{array}$ & [41] \\
\hline \multicolumn{6}{|c|}{ Dysregulated LncRNAs between GSCs and NSCs Comparison } \\
\hline Rheinbay, et al. & 2013 & GSCs vs. NSCs & $\begin{array}{l}\text { 173: LOC399959, LOC645323, } \\
\text { HOTAIRM1, H19, MALAT1, SOX2ot, } \\
\text { et al. }\end{array}$ & $\begin{array}{l}\text { 19: HYMAI, AL133167.1, } \\
\text { FLJ31485, et al. }\end{array}$ & [58] \\
\hline
\end{tabular}

${ }^{1}$ Profiling studies searching was performed in public GEO database (December, 2014). Only the datasets profiled on Affymetrix HG-U133 Plus 2.0 microarray platform were enrolled in our review analysis. With regard to how to process Affymetrix HG-U133 Plus 2.0 raw data and mine lncRNA information from it, please refer to our previous paper for details [43]. ${ }^{2}$ For each individual study reviewed here, the total number of dysregulated lncRNAs, as well as the representative candidates were listed. Representative candidates were defined if they fulfilled one of following the criteria: (1) They were the top 3 dysregulated genes in comparison; (2) They appeared in more than one independent study reviewed at the same dysregulation pattern; (3) They have been functionally reported in public studies, especially in cancer. 


\subsection{Dysregulated LncRNAs during GSC Differentiation}

Comparative analyses of lncRNA expression profiles in GSCs (defined by sphere formation) and their differentiated tumor cell counterparts (induced by adding serum) revealed significant differential lncRNAs dysregulations, indicating the potential roles of lncRNAs in regulating GSCs maintenance and differentiation. For example, Araki et al. examined the lncRNA expression profiles between GSCs derived from four different GBM patient samples and the corresponding differentiated tumor cells, and identified a set of 34 differentially expressed lncRNA transcripts (out of 2448, fold change $\geq 2.0$ ) [47]. Amongst these, the most notable candidate is H19, which was one of most up-regulated lncRNAs in GSCs as compared to the differentiated cells, suggesting that H19 may have a potential role in stemness maintenance in GSCs. In support of this hypothesis, H19 has been reported as a crucial factor for the maintenance of adult haematopoietic stem cells [48].

A subsequent study that compared the gene expression patterns between GSCs and differentiated cells also observed dramatic lncRNA dysregulations. Aldaz et al. performed lncRNA profiling in four patient-derived GSCs (also defined by sphere formation) and the corresponding differentiated tumor cells. This revealed differential expressions of 39 lncRNAs (fold change $\geq 2.0$ ) [42]. The study confirmed the up-regulation of H19 in GSCs, and also identified a large population of novel dysregulated lncRNA candidates. The most striking dysregulations were observed for MIAT, XIST, RP11-346D6.6, C6orf155 and HCG4. Amongst these, MIAT and XIST were found to be up-regulated in GSCs when compared to differentiated cells; RP11-346D6.6, C6orf155 and HCG4 were down-regulated. Consistent with these findings, the up-regulation of XIST was confirmed in another study, in which XIST was found to have higher expression in GSCs and may regulate the GSCs growth both in vitro and in vivo [25].

However, it is important to note that there was little overlap between the lists of dysregulated IncRNAs from the above two studies; the degree of between-study concordance was low. For example, amongst the 34 lncRNAs identified in Araki's study [47] and the 39 in Aldaz's study [42], only four lncRNAs were identified in both studies, including the above mentioned H19. The similar situation was previously reported in miRNA profiling studies in glioma also [49]. The large variability in patient samples, as well as discrepancies in the choice of GSCs-maintaining medium may underlie this disparity.

\subsection{Dysregulated LncRNAs between GSCs with Different Subtypes}

LncRNAs are also differentially expressed in different subtypes of GSCs. It has been reported that GSCs may have different sub-phenotypes and thus growth properties [40,41]. For example, GSCs with positive CD133 expression showed a spherical growth pattern (non-adherent) in vitro and would form highly invasive tumors in vivo, while GSCs with negative CD133 expression demonstrated a semi-adherent (or adherent growth) in culture and reduced tumor invasion in animals [40,41]. Comparative analysis of IncRNA profiles between these two subtypes of GSCs revealed significantly dysregulated lncRNAs, which may provide clues for the molecular mechanisms that underlie the differences in their growth phenotypes. For example, by comparing the lncRNA profiles of three CD133 + GSCs and three CD133 - GSCs, Beier et al. identified a set of 72 differentially expressed lncRNA transcripts (fold change $\geq 2.0$ ) [40]. Among these, the expression levels of XIST, H19, and HOTAIR were markedly higher in the CD133 + GSCs than in the CD133- ones; while the expression 
levels of CTC-231O11.1, RP11-745C15.2, LOC100130776, and C14orf139 were significantly lower in the CD133 + GSCs than in the CD133- ones (Table 1). Of these, the up-regulations of H19 and HOTAIR were confirmed by an independent subsequent study [41]. In support of this hypothesis, H19 and HOTAIR have been reported to increase the propensities for tumor metastasis in bladder cancer and breast cancer [50-52].

\subsection{Dysregulated LncRNAs between GSCs and Neural Stem Cells (NSCs)}

GSCs have similar but not identical characteristics to that in non-malignant NSCs [53-57]. The two cell types share some surface markers, can both divide and give rise to daughter stem cells with capabilities identical to that of the parental cells (self-renewal), and can both differentiate into multiple neural cell types (multipotency) [53-57]. However, unlike NSCs, GSCs act in a dysregulated manner and possess tumorigenic characters when implanted into immune-deficient animals [55]. By comparative analysis of IncRNA expression profiles between GSCs and non-malignant NSCs, Rheinbay et al. revealed the significantly differential expression for HOTAIRM1, H19, MALAT1 and SOX2ot [58]. The dramatic up-regulations of their expressions in GSCs indicate their potential oncogenic roles in the malignant transformation of NSCs. In agreement with this hypothesis, H19, MALAT1 and SOX2ot have been reported to be tumorigenic or to function as metastasis promoters in multiple cancer types [50,59-62].

\section{Functional Roles and Molecular Mechanism of LncRNAs in GSCs}

While the significant IncRNA dysregulations observed above would suggest their potential roles in GSCs, the precise functions and molecular mechanism by which these lncRNAs may operate remain incompletely understood. There is currently little evidence to directly link these lncRNAs with specific cellular processes or signaling pathways in GSCs. However, it has been generally accepted that IncRNAs may function through interactions with their molecular partners, such as proteins and RNAs [19,63,64]. Therefore, analyzing the binding potentials of lncRNAs with their interactive molecules may theoretically help predict the formers' functions and mechanisms.

To decipher the functional roles of lncRNAs in GSCs, we have examined extensively the interactive potentials of various identified lncRNAs with transcription factors (TFs), RNA binding proteins (RBPs) and miRNAs, by using currently available research tools $[65,66]$. It is indeed interesting to find that lncRNAs may show strong binding potentials with some key transcription factors, miRNAs or gene pathways that are also crucial for the "stemness" maintenance in GSCs. A discussion of these findings from bioinformatics analyses by means of publicly available tools [65,66], and with a relevant literature review, is provided in the following sections and in Figure 2. Related interactive transcription factors, miRNAs and RNA binding proteins are summarized in Table 2.

\subsection{Interaction with Stem Cell Transcription Factors (TFs)}

Several transcription factors, such as c-Myc, OCT-4 and Nanog, have been shown to play key roles in promoting and stabilizing the "stem-cell-like" phenotype of non-malignant stem cells and GSCs [67-74]. These factors may activate the expression of a large number of downstream genes, 
enhance self-renewal, and inhibit the differentiation of stem cells through various pathways [67-74]. The IncRNA-TF interaction analysis, based on the ChIP-Seq data, revealed numerous binding sites for key transcription factors in the promoter areas (5 kb upstream and $1 \mathrm{~kb}$ downstream) of these lncRNAs, implying that lncRNAs may act as mediators of these key transcription factors in regulating GSCs maintenance.

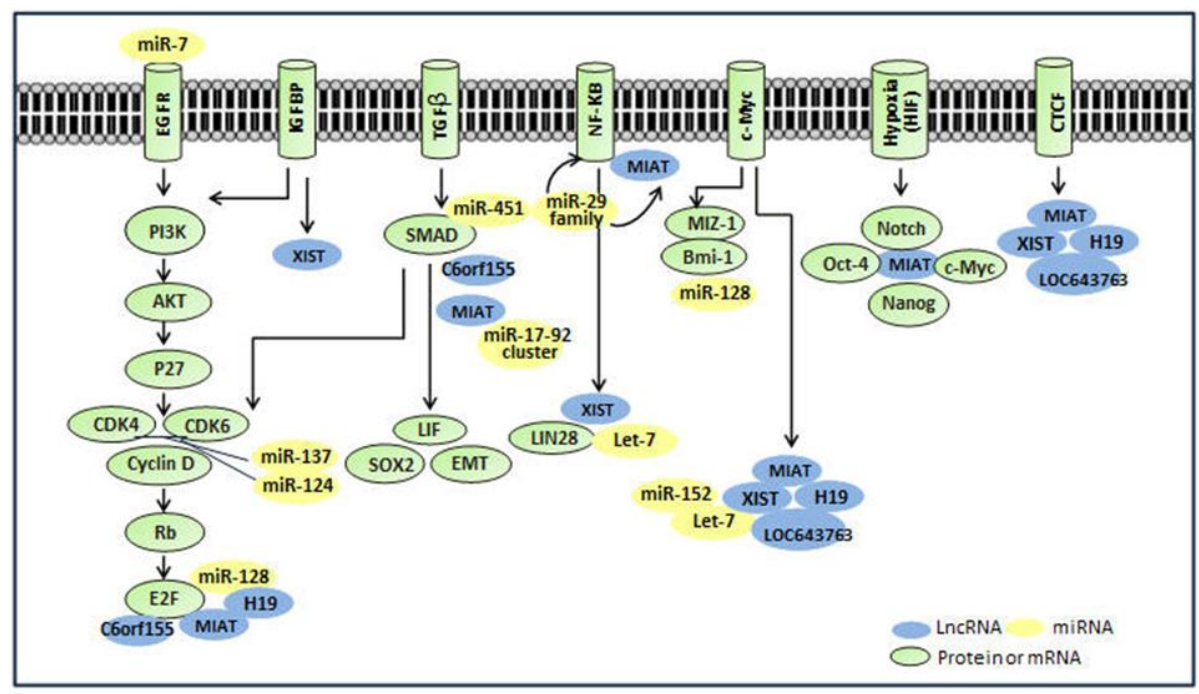

Figure 2. Representative figures of lncRNA interaction with key molecules or cellular processes in GSCs.

Table 2. Interaction of lncRNAs with TFs, miRNAs and RBPs ${ }^{1}$.

\begin{tabular}{|c|c|c|c|}
\hline LncRNAs $^{2}$ & Interactive TFs ${ }^{3}$ (Number of Binding Sites) & Interactive miRNAs $^{3}$ & Interactive RBPs $^{3}$ \\
\hline H19 & NFKB (39), E2F (30), c-Myc (45), CTCF (60) & $\begin{array}{l}\operatorname{miR}-29 a, \operatorname{miR}-29 b, \operatorname{miR}-29 c, \operatorname{miR}-18 a, m i R-19 a \\
\text { miR-20a, miR-19b, et al. }\end{array}$ & NA \\
\hline MIAT & $\begin{array}{l}\text { NFKB (45), E2F (43), Nanog (27), } \\
\text { SMAD (20), c-Myc (15), Oct-4 (5), CTCF (20) }\end{array}$ & $\operatorname{miR}-29 a, \operatorname{miR}-29 b, \operatorname{miR}-29 c$, and $\operatorname{miR}-150$ & NA \\
\hline XIST & $\begin{array}{l}\text { NFKB (18), TAF1 (14), c-Myc (8), CTCF (8), } \\
\text { Nanog (2), HNF4A(6) }\end{array}$ & $\begin{array}{l}\text { miR-124, miR-34a, miR-137, miR-146a, miR-326, } \\
\text { miR-7 and miR-425, miR-152, let-7, et al. }\end{array}$ & LIN28, IGF2BP \\
\hline LOC100127888 & NA & NA & NA \\
\hline RP11-112J3.16 & HNF4A (1) & NA & NA \\
\hline LOC643763 & CTCF (3), c-Myc (1), NFKB (1), Nanog (1) & NA & NA \\
\hline RP11-346D6.6 & CDX2(2), GATA6 (3), HNF4A (3), Nanog (1) & NA & NA \\
\hline FLJ39609 & CDX2(2), c-Myc (1), USF-1 (4) & NA & NA \\
\hline C6orf155 & $\begin{array}{l}\text { CDX2(5), E2F (10), HNF4A (4), } \\
\text { Nanog (5), SMAD (5) }\end{array}$ & NA & NA \\
\hline HCG4 & NA & NA & NA \\
\hline DLX6-AS & NA & NA & NA \\
\hline
\end{tabular}

Abbreviations: TF, transcription factor; RBP, RNA binding protein; NA, not applicable. ${ }^{1}$ The interactions of IncRNAs with miRNAs and RBPs were analyzed by using the public tool starbase v2.0 [Ref.65], and the interactions with TFs were analyzed by using the public tool ChIPBase [66]. Due to space limit. ${ }^{2}$ Only lncRNAs indicated for GSCs maintenance (dysregulated in GSCs and differentiated GBM cells comparison) were enrolled for analysis here. ${ }^{3}$ Only molecules that have been functionally reported in stemness regulation were included in the table. 
An example is MIAT, which is one of the most highly upregulated lncRNAs in GSCs as compared to the differentiated GBM counterparts in Aldaz's study [42]. By screening its promoter area, enriched binding sites were found for all the above three TFs: 27 binding sites for Nanog, 15 for c-Myc and 5 for OCT-4 (Table 2). While the functional role of MIAT in GSCs is not known, MIAT has been reported to interact with OCT-4 and may play regulatory roles in mouse embryonic stem cells [75]. Moreover, MIAT has been found to be dysregulated during the differentiation of normal neural stem cells [76]. Its strong interaction with multiple key stem-cell-associated transcription factors and its significant dysregulation in GSCs suggest that MIAT may play important roles in regulating GSCs, and warrants further studies.

Another interesting example is H19, which was one of the most up-regulated lncRNAs in GSCs as compared to differentiated GBM cells in the two aforementioned studies [42,47]. H19 was found to possess $45 \mathrm{c}-$ Myc binding sites in its promoter area. As the first reported lncRNA in mammalian cells, H19 has been extensively studied in developmental biology as well as oncology during the past two decades [77,78]. Supporting our observation here, Barsyte et al. have shown that c-Myc could significantly induce the expression of $\mathrm{H} 19$ in T98G GBM cells through direct binding [79]. Although the tentative link between H19 and GSCs is yet to be confirmed, H19 has been found to regulate stemness in haematopoietic as well as embryonic stem cells $[48,80]$. How H19 may interact with c-Myc and regulate GSCs growth properties deserves further investigations.

A significant lncRNA-TF interaction was also observed for another stem-cell-associated transcription factor, CTCT. CTCF (CCCTC-binding factor) is a highly conserved multifunctional DNA-binding protein with thousands of binding sites at the genome-wide level [81]. It can act as a transcriptional activator, repressor and insulator. It can also attract many other transcription factors, transcription activators or repressors to chromatin, and can thus play extensive regulatory roles in gene expressions [81,82]. CTCF is associated with some biological processes, including embryonic stem cell differentiation [83], neuronal [84] and haematopoietic development [85,86]. Here, we found that multiple lncRNAs, including H19, MIAT, XIST and LOC643763, contained abundant binding sites with CTCF (Table 2), suggesting the potential roles of CTCF in maintaining GSCs. Of even greater importance are XIST and H19, which contain 20 and 60 CTCF binding sites, respectively. It is therefore an attractive idea to investigate whether and how these lncRNAs would interact with CTCF and play regulatory roles in GSCs. In supporting our observation here, CTCF has actually been reported to mediate the imprinted expression of H19, as well as its neighbor gene IGF2 by means of methylation-dependent binding [87].

\subsection{Interaction with MiRNAs}

GSCs-associated lncRNAs also contained enriched binding sites with miRNAs that have been reported to be functional in GSCs, suggesting that interaction with miRNA may be another potential functional entity of lncRNAs in GSCs. It has been suggested that lncRNAs and miRNAs might participate in a shared competing endogenous RNA (ceRNA) regulatory network, since they may actually regulate each other reciprocally $[88,89]$. In this ceRNA network, miRNA can regulate lncRNAs as they do on mRNAs since lncRNAs also have similar miRNA targeting sites as mRNAs as shown in a recent global analysis of Argonaute (Ago)-bound transcripts using the HITS-CLIP technique [65,90]. 
At the same time, lncRNA can reversely regulate miRNAs through their abilities to compete for miRNA binding, and to act as miRNA sponge or host gene [91-93].

A notable example of IncRNA-miRNA interaction is XIST. This lncRNA was found to possess binding sites with almost all the well-characterized GSCs-associated miRNAs, suggestive of its potential role as a super "miRNA sponge". These include miR-124, 34a, miR-137, miR-146a, miR-326, miR-7 and miR-425 (Table 2). All these miRNAs are down-regulated in GSCs, and may regulate GSCs growth behavior by targeting different downstream targets [35,94]. Additionally, XIST also demonstrates binding potentials with other multiple miRNAs, which have previously not been functionally identified in GSCs. These include miR-152 and let-7 family members. This is in agreement with a recent study, which demonstrated a reciprocal regulation between XIST and miR-152 in GSCs [25]. In this interesting study, the authors first determined that XIST was up-regulated in GSCs, and that the knock-down of XIST would suppress GSCs growth in vitro and tumorigenicity in vivo. Further analyses revealed that there was reciprocal repression between XIST and miR-152: knock-down of XIST may up-regulate miR152, and vice versa [25]. The study provided the earliest evidence of lncRNA-miRNA interactions in GSCs. As for the let-7 family, it has been reported to regulate tumorigenicity in breast cancer stem cells [95]. The enriched binding targets existed for almost all the let-7 family members in XIST (let-7a, b, c, $\mathrm{d}, \mathrm{e}, \mathrm{f}, \mathrm{g}$ ). Together with other evidence (detailed in 4.3 below), these findings suggested that XIST may be another potential target in GSCs regulating.

Significant lncRNA-miRNA interactions have also been observed for MIAT and H19 (Table 2). Both may act as the targets for miR-29 family ( $a, b, c)$, which has been widely reported to regulate cell proliferation, migration, invasion and tumorigenesis in GBM [42,96,97]. Additionally, H19 was found to possess targeting sites for multiple members of the miR-17-92 cluster. The latter has previously been implicated in the regulation of GBM neurosphere formation (presumably stem cells), differentiation, apoptosis and proliferation [98]. Inhibition of miR-17-92 reduced apoptosis and decreased cell proliferation in GBM neurospheres. These findings therefore indicated that H19-miR-17-92 cluster interaction may be one of possible ways in mediating the GSCs maintenance and differentiation.

\subsection{Interaction with NFKB Pathways}

The presence of extensive direct binding sites for NFKB or other key member genes in NFKB suggest the potential involvement of lncRNAs in this important signaling pathway. NFKB is a transcription factor and an inducer of signal pathway in glioma [99]. NFKB has been reported to regulate GSCs maintenance independently or in conjunction with the STAT and Notch pathways [100,101]. It was found that MIAT has 45 binding sites with NFKB in its promoter area, suggesting the involvement of NFKB and MIAT in each other's signaling pathway. Another piece of supporting evidence for there being a connection between MIAT with NFKB pathway is their interactions with miR-29. As mentioned above, MIAT has enriched target sites for miR-29. It is interesting to found that miR-29 is also an important mediator of NFKB. NFKB could suppress miR-29 transcription and promoter function. It is thus tempting to speculate whether NFKB, miR-29 and MIAT may interact.

Another lncRNA that showed interactions with NFKB is, again, XIST. The direct evidence is that XIST possess 18 NFKB binding sites in its promoter area. The indirect evidence is that XIST may interact with LIN28, a key member of NFKB pathway [102]. LIN28 is a conserved RNA-binding 
protein (RBP) implicated for pluripotency, reprogramming, and oncogenesis [103-106]. It was previously shown that Lin28 expression could be activated directly by NFKB [102]. At the same time, LIN28 was able to decrease let-7 miRNA levels [102,107-109], and as well as the other downstream effects, such as the activation of STAT3 transcription factor [110]. This NFKB-LIN28-let-7 axis has been reported to be able to transform immortalized breast cells into self-renewing mammospheres that contain CSCs [102]. The interactions of XIST with NFKB, LIN28 and let-7 family mentioned above indicate the possible roles of XIST in maintaining GSCs properties through this axis. The detailed interactive mechanisms of XIST in this axis, however, need to be further studied.

\subsection{Interaction with Other Molecules or Pathways}

LncRNAs also has the tendency to interact with other well-characterized molecules or important cellular processes in GSCs. A detailed description is beyond the scope of this review. To cite an example, MIAT has been shown to be involved in TGF-beta signaling, since the former has 20 binding sites for the key signal transducer gene of the latter pathway-SMAD [111-113]. Three lncRNAs, including RP11-346D6.6, FLJ39609 and C6orf155, possess enriched binding sites with CDX2, indicating the potential interactions of lncRNAs in CDX2-mediated cellular processes crucial for the pluripotency maintenance [114]. Another three lncRNAs, C6orf155, MIAT and H19, also showed strong interactions with the cell-cycle gene E2F, an important family of transcription factors that regulate cell cycle progression and thus cell proliferation [115-117].

\section{Conclusions}

Growing evidence has shown that GSCs, which possess resistance to radiation therapy and chemotherapy, are responsible for tumor initiation and propagation in GBM. These characteristics indicate that GSCs are promising therapeutic targets, and that eliminating GSCs may improve patient outcome. Successful targeted therapies depend heavily on the identification of unique markers and signaling pathways in GSCs that can distinguish them from both normal and the non-GSC tumor cells. The functional significance of lncRNAs in GBM and other cancer types is beginning to emerge. The identification of lncRNAs that are dysregulated in GSCs, as well as their potential functional mechanisms, will present researchers with many opportunities for the studying of GBM initiation and progression as well as the development of future treatment for glioma. Further researches are needed to identify and verify the functions of different lncRNAs in not only GBM but also other cancers.

\section{Acknowledgments}

We thank Ming-Fai Poon, Stephen Cheung and Ning Li for their valuable discussions.

\section{Author Contributions}

Xiaoqin Zhang performed literature review, data analysis and wrote the manuscript. Karrie Meiyee Kiang collected and assembled datasets. Grace Pingde Zhang prepared the tables and revised the manuscript. Gilberto Kakit Leung conceived the study and revised the manuscript. 


\section{Conflicts of Interest}

The authors declared no conflicts of interests.

\section{References}

1. Lobo, N.A.; Shimono, Y.; Qian, D.; Clarke, M.F. The biology of cancer stem cells. Ann. Rev. Cell Dev. Biol. 2007, 23, 675-699.

2. Clevers, H. The cancer stem cell: Premises, promises and challenges. Nat. Med. 2011, 17, 313-319.

3. Frank, N.Y.; Schatton, T.; Frank, M.H. The therapeutic promise of the cancer stem cell concept. J. Clin. Investig. 2010, 120, 41-50.

4. Chen, K.; Huang, Y.H.; Chen, J.L. Understanding and targeting cancer stem cells: Therapeutic implications and challenges. Acta Pharmacol. Sin. 2013, 34, 732-740.

5. Hemmati, H.D.; Nakano, I.; Lazareff, J.A.; Masterman-Smith, M.; Geschwind, D.H.; Bronner-Fraser, M.; Kornblum, H.I. Cancerous stem cells can arise from pediatric brain tumors. PNAS 2003, 100, 15178-15183.

6. Singh, S.K.; Hawkins, C.; Clarke, I.D.; Squire, J.A.; Bayani, J.; Hide, T.; Henkelman, R.M.; Cusimano, M.D.; Dirks, P.B. Identification of human brain tumour initiating cells. Nature 2004, 432, 396-401.

7. Galli, R.; Binda, E.; Orfanelli, U.; Cipelletti, B.; Gritti, A.; de Vitis, S.; Fiocco, R.; Foroni, C.; Dimeco, F.; Vescovi, A. Isolation and characterization of tumorigenic, stem-like neural precursors from human glioblastoma. Cancer Res. 2004, 64, 7011-7021.

8. Rich, J.N.; Eyler, C.E. Cancer stem cells in brain tumor biology. Cold Spring Harb. Symp. Quant. Biol. 2008, 73, 411-420.

9. Ahmed, A.U.; Auffinger, B.; Lesniak, M.S. Understanding glioma stem cells: Rationale, clinical relevance and therapeutic strategies. Exp. Rev. Neurother. 2013, 13, 545-555.

10. Cho, D.Y.; Lin, S.Z.; Yang, W.K.; Lee, H.C.; Hsu, D.M.; Lin, H.L.; Chen, C.C.; Liu, C.L.; Lee, W.Y.; Ho, L.H. Targeting cancer stem cells for treatment of glioblastoma multiforme. Cell Transplant. 2013, 22, 731-739.

11. Frosina, G. Frontiers in targeting glioma stem cells. Eur. J. Cancer 2011, 47, 496-507.

12. Stupp, R.; Hegi, M.E. Targeting brain-tumor stem cells. Nat. Biotechnol. 2007, 25, 193-194.

13. Ciechomska, I.A.; Kocyk, M.; Kaminska, B. Glioblastoma stem-like cells-isolation, biology and mechanisms of chemotherapy resistance. Curr. Signal Transduct. Ther. 2013, 8, 256-267.

14. Yamada, K.; Tso, J.; Ye, F.; Choe, J.; Liu, Y.; Liau, L.M.; Tso, C.L. Essential gene pathways for glioblastoma stem cells: Clinical implications for prevention of tumor recurrence. Cancers 2011, 3, 1975-1995.

15. Gutschner, T.; Diederichs, S. The hallmarks of cancer: A long non-coding rna point of view. RNA Biol. 2012, 9, 703-719.

16. Gibb, E.A.; Brown, C.J.; Lam, W.L. The functional role of long non-coding RNA in human carcinomas. Mol. Cancer 2011, 10, 38.

17. Cao, J. The functional role of long non-coding RNAs and epigenetics. Biol. Proced. Online 2014, 16, 11, doi:10.1186/1480-9222-16-11. 
18. Mercer, T.R.; Dinger, M.E.; Mattick, J.S. Long non-coding RNAs: Insights into functions. Nat. Rev. Genet. 2009, 10, 155-159.

19. Wang, K.C.; Chang, H.Y. Molecular mechanisms of long noncoding RNAs. Mol. Cell 2011, 43, 904-914.

20. Wang, P.; Ren, Z.; Sun, P. Overexpression of the long non-coding RNA MEG3 impairs in vitro glioma cell proliferation. J. Cell. Biochem. 2012, 113, 1868-1874.

21. Zhang, K.; Sun, X.; Zhou, X.; Han, L.; Chen, L.; Shi, Z.; Zhang, A.; Ye, M.; Wang, Q.; Liu, C.; et al. Long non-coding RNA hotair promotes glioblastoma cell cycle progression in an EZH2 dependent manner. Oncotarget 2015, 6, 537-546.

22. Shi, Y.; Wang, Y.; Luan, W.; Wang, P.; Tao, T.; Zhang, J.; Qian, J.; Liu, N.; You, Y. Long non-coding RNA H19 promotes glioma cell invasion by deriving MIR-675. PLoS ONE 2014, 9, e86295.

23. Ma, K.X.; Wang, H.J.; Li, X.R.; Li, T.; Su, G.; Yang, P.; Wu, J.W. Long noncoding RNA MALAT1 associates with the malignant status and poor prognosis in glioma. Tumour Biol. 2015, 36, 3355-3359.

24. Park, J.Y.; Lee, J.E.; Park, J.B.; Yoo, H.; Lee, S.H.; Kim, J.H. Roles of long non-coding RNAs on tumorigenesis and glioma development. Brain Tumor Res. Treat. 2014, 2, 1-6.

25. Yao, Y.; Ma, J.; Xue, Y.; Wang, P.; Li, Z.; Liu, J.; Chen, L.; Xi, Z.; Teng, H.; Wang, Z.; et al. Knockdown of long non-coding RNA xist exerts tumor-suppressive functions in human glioblastoma stem cells by up-regulating MIR-152. Cancer Lett. 2015, 359, 75-86.

26. Clarke, M.F.; Dick, J.E.; Dirks, P.B.; Eaves, C.J.; Jamieson, C.H.; Jones, D.L.; Visvader, J.; Weissman, I.L.; Wahl, G.M. Cancer stem cells-perspectives on current status and future directions: AACR workshop on cancer stem cells. Cancer Res. 2006, 66, 9339-9344.

27. Sampetrean, O.; Saya, H. Characteristics of glioma stem cells. Brain Tumor Pathol. 2013, 30, 209-214.

28. Gursel, D.B.; Shin, B.J.; Burkhardt, J.K.; Kesavabhotla, K.; Schlaff, C.D.; Boockvar, J.A. Glioblastoma stem-like cells-biology and therapeutic implications. Cancers 2011, 3, 2655-2666.

29. Eramo, A.; Ricci-Vitiani, L.; Zeuner, A.; Pallini, R.; Lotti, F.; Sette, G.; Pilozzi, E.; Larocca, L.M.; Peschle, C.; De Maria, R. Chemotherapy resistance of glioblastoma stem cells. Cell Death Differ. 2006, 13, 1238-1241.

30. Bao, S.; Wu, Q.; McLendon, R.E.; Hao, Y.; Shi, Q.; Hjelmeland, A.B.; Dewhirst, M.W.; Bigner, D.D.; Rich, J.N. Glioma stem cells promote radioresistance by preferential activation of the DNA damage response. Nature 2006, 444, 756-760.

31. Lee, J.; Kotliarova, S.; Kotliarov, Y.; Li, A.G.; Su, Q.; Donin, N.M.; Pastorino, S.; Purow, B.W.; Christopher, N.; Zhang, W.; et al. Tumor stem cells derived from glioblastomas cultured in BFGF and EGF more closely mirror the phenotype and genotype of primary tumors than do serum-cultured cell lines. Cancer Cell 2006, 9, 391-403.

32. Liu, Q.; Nguyen, D.H.; Dong, Q.; Shitaku, P.; Chung, K.; Liu, O.Y.; Tso, J.L.; Liu, J.Y.; Konkankit, V.; Cloughesy, T.F.; et al. Molecular properties of CD133 + glioblastoma stem cells derived from treatment-refractory recurrent brain tumors. J. Neuro-Oncol. 2009, 94, 1-19.

33. Pointer, K.B.; Clark, P.A.; Zorniak, M.; Alrfaei, B.M.; Kuo, J.S. Glioblastoma cancer stem cells: Biomarker and therapeutic advances. Neurochem. Int. 2014, 71, 1-7. 
34. Stiles, C.D.; Rowitch, D.H. Glioma stem cells: A midterm exam. Neuron 2008, 58, 832-846.

35. Chu, P.M.; Ma, H.I.; Chen, L.H.; Chen, M.T.; Huang, P.I.; Lin, S.Z.; Chiou, S.H. Deregulated microRNAs identified in isolated glioblastoma stem cells: An overview. Cell Transplant. 2013, $22,741-753$.

36. Mizrak, D.; Brittan, M.; Alison, M. CD133: Molecule of the moment. J. Pathol. 2008, 214, 3-9.

37. Wu, Y.J.; Wu, P.Y. CD133 as a marker for cancer stem cells: Progresses and concerns. Stem. Cells Dev. 2009, 18, 1127-1134.

38. Yuan, X.; Curtin, J.; Xiong, Y.; Liu, G.; Waschsmann-Hogiu, S.; Farkas, D.L.; Black, K.L.; $\mathrm{Yu}, \mathrm{J} . \mathrm{S}$. Isolation of cancer stem cells from adult glioblastoma multiforme. Oncogene 2004, 23, 9392-9400.

39. Liu, G.; Yuan, X.; Zeng, Z.; Tunici, P.; Ng, H.; Abdulkadir, I.R.; Lu, L.; Irvin, D.; Black, K.L.; $\mathrm{Yu}$, J.S. Analysis of gene expression and chemoresistance of CD133 + cancer stem cells in glioblastoma. Mol. Cancer 2006, 5, 67.

40. Beier, D.; Hau, P.; Proescholdt, M.; Lohmeier, A.; Wischhusen, J.; Oefner, P.J.; Aigner, L.; Brawanski, A.; Bogdahn, U.; Beier, C.P. CD133(+) and CD133(-) glioblastoma-derived cancer stem cells show differential growth characteristics and molecular profiles. Cancer Res. 2007, 67, 4010-4015.

41. Gunther, H.S.; Schmidt, N.O.; Phillips, H.S.; Kemming, D.; Kharbanda, S.; Soriano, R.; Modrusan, Z.; Meissner, H.; Westphal, M.; Lamszus, K. Glioblastoma-derived stem cell-enriched cultures form distinct subgroups according to molecular and phenotypic criteria. Oncogene 2008, 27, 2897-2909.

42. Aldaz, B.; Sagardoy, A.; Nogueira, L.; Guruceaga, E.; Grande, L.; Huse, J.T.; Aznar, M.A.; Diez-Valle, R.; Tejada-Solis, S.; Alonso, M.M.; et al. Involvement of miRNAs in the differentiation of human glioblastoma multiforme stem-like cells. PLOS ONE 2013, 8, e77098.

43. Zhang, X.; Sun, S.; Pu, J.K.; Tsang, A.C.; Lee, D.; Man, V.O.; Lui, W.M.; Wong, S.T.; Leung, G.K. Long non-coding RNA expression profiles predict clinical phenotypes in glioma. Neurobiol. Dis. 2012, 48, 1-8.

44. Zhang, X.Q.; Sun, S.; Lam, K.F.; Kiang, K.M.; Pu, J.K.; Ho, A.S.; Lui, W.M.; Fung, C.F.; Wong, T.S.; Leung, G.K. A long non-coding RNA signature in glioblastoma multiforme predicts survival. Neurobiol. Dis. 2013, 58, 123-131.

45. Michelhaugh, S.K.; Lipovich, L.; Blythe, J.; Jia, H.; Kapatos, G.; Bannon, M.J. Mining affymetrix microarray data for long non-coding RNAs: Altered expression in the nucleus accumbens of heroin abusers. J. Neurochem. 2011, 116, 459-466.

46. Johnson, R. Long non-coding RNAs in huntington's disease neurodegeneration. Neurobiol. Dis. 2012, 46, 245-254.

47. Araki, N.; Niibori, A.; Midorikawa, U. Expression profiling of glioma initiating cells (GICs) in the sphere and differentiation conditions. Unpublished results. The raw microarray data is accessible at public NCBI GEO database. Accession No. GSE43762. 2013.

48. Venkatraman, A.; He, X.C.; Thorvaldsen, J.L.; Sugimura, R.; Perry, J.M.; Tao, F.; Zhao, M.; Christenson, M.K.; Sanchez, R.; Yu, J.Y.; et al. Maternal imprinting at the H19-IGF2 locus maintains adult haematopoietic stem cell quiescence. Nature 2013, 500, 345-349. 
49. Zhang, X.Q.; Leung, G.K. Functional roles of non-coding RNAs in glioma and their clinical perspectives. Neurochem. Int. 2014, 77, 78-85.

50. Luo, M.; Li, Z.; Wang, W.; Zeng, Y.; Liu, Z.; Qiu, J. Long non-coding RNA H19 increases bladder cancer metastasis by associating with EZH2 and inhibiting E-cadherin expression. Cancer Lett. 2013, 333, 213-221.

51. Matouk, I.J.; Raveh, E.; Abu-lail, R.; Mezan, S.; Gilon, M.; Gershtain, E.; Birman, T.; Gallula, J.; Schneider, T.; Barkali, M.; et al. Oncofetal H19 RNA promotes tumor metastasis. BBA 2014, 1843, 1414-1426.

52. Gupta, R.A.; Shah, N.; Wang, K.C.; Kim, J.; Horlings, H.M.; Wong, D.J.; Tsai, M.C.; Hung, T.; Argani, P.; Rinn, J.L.; et al. Long non-coding RNA hotair reprograms chromatin state to promote cancer metastasis. Nature 2010, 464, U1071-U1148.

53. Morfouace, M.; Lalier, L.; Bahut, M.; Bonnamain, V.; Naveilhan, P.; Guette, C.; Oliver, L.; Gueguen, N.; Reynier, P.; Vallette, F.M. Comparison of spheroids formed by rat glioma stem cells and neural stem cells reveals differences in glucose metabolism and promising therapeutic applications. J. Biol. Chem. 2012, 287, 33664-33674.

54. Lang, M.F.; Yang, S.; Zhao, C.N.; Sun, G.Q.; Murai, K.; Wu, X.W.; Wang, J.H.; Gao, H.L.; Brown, C.E.; Liu, X.X.; et al. Genome-wide profiling identified a set of miRNAs that are differentially expressed in glioblastoma stem cells and normal neural stem cells. PLoS ONE 2012, 7, e36248.

55. Sanai, N.; Alvarez-Buylla, A.; Berger, M.S. Mechanisms of disease: Neural stem cells and the origin of gliomas. N. Engl. J. Med. 2005, 353, 811-822.

56. Engstrom, P.G.; Tommei, D.; Stricker, S.H.; Ender, C.; Pollard, S.M.; Bertone, P. Digital transcriptome profiling of normal and glioblastoma-derived neural stem cells identifies genes associated with patient survival. Genome Med. 2012, 4, 76, doi:10.1186/gm377.

57. Sandberg, C.J.; Altschuler, G.; Jeong, J.; Stromme, K.K.; Stangeland, B.; Murrell, W.; Grasmo-Wendler, U.H.; Myklebost, O.; Helseth, E.; Vik-Mo, E.O.; et al. Comparison of glioma stem cells to neural stem cells from the adult human brain identifies dysregulated Wnt-signaling and a fingerprint associated with clinical outcome. Exp. Cell Res. 2013, 319, 2230-2243.

58. Rheinbay, E.; Suva, M.L.; Gillespie, S.M.; Wakimoto, H.; Patel, A.P.; Shahid, M.; Oksuz, O.; Rabkin, S.D.; Martuza, R.L.; Rivera, M.N.; et al. An aberrant transcription factor network essential for Wnt signaling and stem cell maintenance in glioblastoma. Cell Rep. 2013, 3, 1567-1579.

59. Hou, Z.B.; Zhao, W.; Zhou, J.; Shen, L.; Zhan, P.; Xu, C.H.; Chang, C.J.; Bi, H.; Zou, J.; Yao, X.; et al. A long noncoding RNA Sox2ot regulates lung cancer cell proliferation and is a prognostic indicator of poor survival. Int. J. Biochem. Cell Biol. 2014, 53, 380-388.

60. Askarian-Amiri, M.E.; Seyfoddin, V.; Smart, C.E.; Wang, J.L.; Kim, J.E.; Hansji, H.; Baguley, B.C.; Finlay, G.J.; Leung, E.Y. Emerging role of long non-coding RNA Sox2ot in Sox2 regulation in breast cancer. PLOS ONE 2014, 9, e102140.

61. Gutschner, T.; Hammerle, M.; Eissmann, M.; Hsu, J.; Kim, Y.; Hung, G.; Revenko, A.; Arun, G.; Stentrup, M.; Gross, M.; et al. The noncoding RNA malat1 is a critical regulator of the metastasis phenotype of lung cancer cells. Cancer Res. 2013, 73, 1180-1189. 
62. Matouk, I.J.; Mezan, S.; Mizrahi, A.; Ohana, P.; Abu-Lail, R.; Fellig, Y.; Degroot, N.; Galun, E.; Hochberg, A. The oncofetal H19 RNA connection: Hypoxia, p53 and cancer. Biochim. Biophys. Acta 2010, 1803, 443-451.

63. Rinn, J.L.; Chang, H.Y. Genome regulation by long noncoding RNAs. Ann. Rev. Biochem. 2012, 81, 145-166.

64. Zhu, J.; Fu, H.; Wu, Y.; Zheng, X. Function of lncrnas and approaches to IncRNA-protein interactions. Sci. China Life Sci. 2013, 56, 876-885.

65. Li, J.H.; Liu, S.; Zhou, H.; Qu, L.H.; Yang, J.H. Starbase v2.0: Decoding miRNA-ceRNA, miRNA-ncRNA and protein-RNA interaction networks from large-scale CLIP-Seq data. Nucleic Acids Res. 2014, 42, D92-D97.

66. Yang, J.H.; Li, J.H.; Jiang, S.; Zhou, H.; Qu, L.H. Chipbase: A database for decoding the transcriptional regulation of long non-coding RNA and microrna genes from CHIP-Seq data. Nucleic Acids Res. 2013, 41, D177-D187.

67. Wang, J.L.; Wang, H.; Li, Z.Z.; Wu, Q.L.; Lathia, J.D.; McLendon, R.E.; Hjelmeland, A.B.; Rich, J.N. c-Myc is required for maintenance of glioma cancer stem cells. PLoS ONE 2008, 3, e3769

68. Chiou, S.H.; Wang, M.L.; Chou, Y.T.; Chen, C.J.; Hong, C.F.; Hsieh, W.J.; Chang, H.T.; Chen, Y.S.; Lin, T.W.; Hsu, H.S.; et al. Coexpression of Oct4 and nanog enhances malignancy in lung adenocarcinoma by inducing cancer stem cell-like properties and epithelial-mesenchymal transdifferentiation. Cancer Res. 2010, 70, 10433-10444.

69. Jeter, C.R.; Liu, B.; Liu, X.; Chen, X.; Liu, C.; Calhoun-Davis, T.; Repass, J.; Zaehres, H.; Shen, J.J.; Tang, D.G. Nanog promotes cancer stem cell characteristics and prostate cancer resistance to androgen deprivation. Oncogene 2011, 30, 3833-3845.

70. Moon, J.H.; Kwon, S.; Jun, E.K.; Kim, A.; Whang, K.Y.; Kim, H.; Oh, S.; Yoon, B.S.; You, S. Nanog-induced dedifferentiation of p53-deficient mouse astrocytes into brain cancer stem-like cells. Biochem. Biophys. Res. Commun. 2011, 412, 175-181.

71. Kumar, S.M.; Liu, S.; Lu, H.; Zhang, H.; Zhang, P.J.; Gimotty, P.A.; Guerra, M.; Guo, W.; Xu, X. Acquired cancer stem cell phenotypes through Oct4-mediated dedifferentiation. Oncogene 2012, 31, 4898-4911.

72. Samardzija, C.; Quinn, M.; Findlay, J.K.; Ahmed, N. Attributes of Oct4 in stem cell biology: Perspectives on cancer stem cells of the ovary. J. Ovarian Res. 2012, 5, 37.

73. Morfouace, M.; Lalier, L.; Oliver, L.; Cheray, M.; Pecqueur, C.; Cartron, P.F.; Vallette, F.M. Control of glioma cell death and differentiation by PKM2-Oct4 interaction. Cell Death Dis. 2014, 5, e1036, doi:10.1038/cddis.2013.561.

74. Schwarz, B.A.; Bar-Nur, O.; Silva, J.C.R.; Hochedlinger, K. Nanog is dispensable for the generation of induced pluripotent stem cells. Curr. Biol. 2014, 24, 347-350.

75. Mohamed, J.S.; Gaughwin, P.M.; Lim, B.; Robson, P.; Lipovich, L. Conserved long noncoding RNAs transcriptionally regulated by Oct 4 and nanog modulate pluripotency in mouse embryonic stem cells. RNA 2010, 16, 324-337.

76. Mercer, T.R.; Qureshi, I.A.; Gokhan, S.; Dinger, M.E.; Li, G.Y.; Mattick, J.S.; Mehler, M.F. Long noncoding RNAs in neuronal-glial fate specification and oligodendrocyte lineage maturation. BMC Neurosci. 2010, 11, 14, doi:10.1186/1471-2202-11-14. 
77. Ratajczak, M.Z. IGF2-H19, an imprinted tandem gene, is an important regulator of embryonic development, a guardian of proliferation of adult pluripotent stem cells, a regulator of longevity, and a "passkey" to cancerogenesis. Folia Histochem. Cytobiol. 2012, 50, 171-179.

78. Gabory, A.; Jammes, H.; Dandolo, L. The h19 locus: Role of an imprinted non-coding RNA in growth and development. Bioessays 2010, 32, 473-480.

79. Barsyte-Lovejoy, D.; Lau, S.K.; BoutroS, P.C.; Khosravi, F.; Jurisica, I.; Andrulis, I.L.; Tsao, M.S.; Penn, L.Z. The c-Myc oncogene directly induces the H19 noncoding RNA by allele-specific binding to potentiate tumorigenesis. Cancer Res. 2006, 66, 5330-5337.

80. Yin, Y.; Wang, H.; Liu, K.; Wang, F.; Ye, X.; Liu, M.; Xiang, R.; Liu, N.; Liu, L. Knockdown of $\mathrm{H} 19$ enhances differentiation capacity to epidermis of parthenogenetic embryonic stem cells. Curr. Mol. Med. 2014, 14, 737-748.

81. Holwerda, S.J.; de Laat, W. CTCF: The protein, the binding partners, the binding sites and their chromatin loops. Philo. Trans. R. Soc. Lond. B Biol. Sci. 2013, 368, 20120369.

82. Herold, M.; Bartkuhn, M.; Renkawitz, R. CTCF: Insights into insulator function during development. Development 2012, 139, 1045-1057.

83. Plasschaert, R.N.; Vigneau, S.; Tempera, I.; Gupta, R.; Maksimoska, J.; Everett, L.; Davuluri, R.; Mamorstein, R.; Lieberman, P.M.; Schultz, D.; et al. CTCF binding site sequence differences are associated with unique regulatory and functional trends during embryonic stem cell differentiation. Nucleic Acids Res. 2014, 42, 774-789.

84. Sone, M.; Hayashi, T.; Tarui, H.; Agata, K.; Takeichi, M.; Nakagawa, S. The mRNA-like noncoding RNA gomafu constitutes a novel nuclear domain in a subset of neurons. J. Cell Sci. 2007, 120, 2498-2506.

85. Hirayama, T.; Tarusawa, E.; Yoshimura, Y.; Galjart, N.; Yagi, T. CTCF is required for neural development and stochastic expression of clustered Pcdh genes in neurons. Cell Rep. 2012, 2, 345-357.

86. Koesters, C.; Unger, B.; Bilic, I.; Schmidt, U.; Bluml, S.; Lichtenberger, B.; Schreiber, M.; Stockl, J.; Ellmeier, W. Regulation of dendritic cell differentiation and subset distribution by the zinc finger protein CTCF. Immunol. Lett. 2007, 109, 165-174.

87. Kurukuti, S.; Tiwari, V.K.; Tavoosidana, G.; Pugacheva, E.; Murrell, A.; Zhao, Z.H.; Lobanenkov, V.; Reik, W.; Ohlsson, R. CTCF binding at the H19 imprinting control region mediates maternally inherited higher-order chromatin conformation to restrict enhancer access to IGF2. PNAS 2006, 103, 10684-10689.

88. Salmena, L.; Poliseno, L.; Tay, Y.; Kats, L.; Pandolfi, P.P. A ceRNA hypothesis: The rosetta stone of a hidden RNA language? Cell 2011, 146, 353-358.

89. Kartha, R.V.; Subramanian, S. Competing endogenous RNAs (ceRNAs): New entrants to the intricacies of gene regulation. Front. Genet. 2014, 5, 8, doi:10.3389/fgene.2014.00008.

90. Chi, S.W.; Zang, J.B.; Mele, A.; Darnell, R.B. Argonaute hits-clip decodes microRNA-mRNA interaction maps. Nature 2009, 460, 479-486.

91. Ebert, M.S.; Neilson, J.R.; Sharp, P.A. Microrna sponges: Competitive inhibitors of small RNAs in mammalian cells. Nat. Method. 2007, 4, 721-726. 
92. Wang, J.Y.; Liu, X.F.; Wu, H.C.; Ni, P.H.; Gu, Z.D.; Qiao, Y.X.; Chen, N.; Sun, F.Y.; Fan, Q.S. Creb up-regulates long non-coding RNA, hulc expression through interaction with microRNA-372 in liver cancer. Nucleic Acids Res. 2010, 38, 5366-5383.

93. Cai, X.Z.; Cullen, B.R. The imprinted H19 noncoding RNA is a primary microRNA precursor. RNA 2007, 13, 313-316.

94. Zhang, Y.; Dutta, A.; Abounader, R. The role of microRNAs in glioma initiation and progression. Front. Biosci. 2012, 17, 700-712.

95. Yu, F.; Yao, H.; Zhu, P.; Zhang, X.; Pan, Q.; Gong, C.; Huang, Y.; Hu, X.; Su, F.; Lieberman, J.; et al. Let-7 regulates self renewal and tumorigenicity of breast cancer cells. Cell 2007, 131, 1109-1123.

96. Fan, Y.C.; Mei, P.J.; Chen, C.; Miao, F.A.; Zhang, H.; Li, Z.L. Mir-29c inhibits glioma cell proliferation, migration, invasion and angiogenesis. J. Neuro-Oncol. 2013, 115, 179-188.

97. Wang, Y.; Li, Y.; Sun, J.; Wang, Q.; Sun, C.; Yan, Y.; Yu, L.; Cheng, D.; An, T.; Shi, C.; et al. Tumor-suppressive effects of miR-29c on gliomas. Neuroreport 2013, 24, 637-645.

98. Ernst, A.; Campos, B.; Meier, J.; Devens, F.; Liesenberg, F.; Wolter, M.; Reifenberger, G.; Herold-Mende, C.; Lichter, P.; Radlwimmer, B. De-repression of CTGF via the miR-17-92 cluster upon differentiation of human glioblastoma spheroid cultures. Oncogene 2010, 29, 3411-3422.

99. Atkinson, G.P.; Nozell, S.E.; Benveniste, E.T. NF-kappaB and STAT3 signaling in glioma: Targets for future therapies. Exp. Rev. Neurother. 2010, 10, 575-586.

100. Garner, J.M.; Fan, M.; Yang, C.H.; Du, Z.; Sims, M.; Davidoff, A.M.; Pfeffer, L.M. Constitutive activation of signal transducer and activator of transcription 3 (STAT3) and nuclear factor kappaB signaling in glioblastoma cancer stem cells regulates the notch pathway. J. Biol. Chem. 2013, 288, 26167-26176.

101. Hjelmeland, A.B.; Wu, Q.; Wickman, S.; Eyler, C.; Heddleston, J.; Shi, Q.; Lathia, J.D.; Macswords, J.; Lee, J.; McLendon, R.E.; et al. Targeting a20 decreases glioma stem cell survival and tumor growth. PLoS Biol. 2010, 8, e1000319.

102. Iliopoulos, D.; Hirsch, H.A.; Struhl, K. An epigenetic switch involving NF-kappaB, Lin28, Let-7 microRNA, and IL6 links inflammation to cell transformation. Cell 2009, 139, 693-706.

103. Yu, J.; Vodyanik, M.A.; Smuga-Otto, K.; Antosiewicz-Bourget, J.; Frane, J.L.; Tian, S.; Nie, J.; Jonsdottir, G.A.; Ruotti, V.; Stewart, R.; et al. Induced pluripotent stem cell lines derived from human somatic cells. Science 2007, 318, 1917-1920.

104. Moss, E.G.; Lee, R.C.; Ambros, V. The cold shock domain protein Lin 28 controls developmental timing in c-Elegans and is regulated by the Lin-4 RNA. Cell 1997, 88, 637-646.

105. Shyh-Chang, N.; Zhu, H.; Yvanka de Soysa, T.; Shinoda, G.; Seligson, M.T.; Tsanov, K.M.; Nguyen, L.; Asara, J.M.; Cantley, L.C.; Daley, G.Q. Lin28 enhances tissue repair by reprogramming cellular metabolism. Cell 2013, 155, 778-792.

106. Zhou, J.; Ng, S.B.; Chng, W.J. Lin28/lin28b: An emerging oncogenic driver in cancer stem cells. Int. J. Biochem. Cell Biol. 2013, 45, 973-978.

107. Qin, R.; Zhou, J.X.; Chen, C.; Xu, T.; Yan, Y.; Ma, Y.S.; Zheng, Z.L.; Shen, Y.P.; Lu, Y.C.; $\mathrm{Fu}, \mathrm{D}$; et al. Lin28 is involved in glioma carcinogenesis and predicts outcomes of glioblastoma multiforme patients. PLOS ONE 2014, 9, e86446. 
108. Viswanathan, S.R.; Daley, G.Q.; Gregory, R.I. Selective blockade of microrna processing by Lin28. Science 2008, 320, 97-100.

109. Ali, P.S.S.; Ghoshdastider, U.; Hoffmann, J.; Brutschy, B.; Filipek, S. Recognition of the Let-7g miRNA precursor by human Lin28b. FEBS Lett. 2012, 586, 3986-3990.

110. Guo, L.; Chen, C.; Shi, M.; Wang, F.; Chen, X.; Diao, D.; Hu, M.; Yu, M.; Qian, L.; Guo, N. STAT3-coordinated Lin-28-Let-7-Hmga2 and Mir-200-Zeb1 circuits initiate and maintain oncostatin m-Driven epithelial-mesenchymal transition. Oncogene 2013, 32, 5272-5282.

111. Derynck, R.; Zhang, Y.E. Smad-dependent and smad-independent pathways in TGF-beta family signalling. Nature 2003, 425, 577-584.

112. Miyazono, K.; ten Dijke, P.; Heldin, C.H. TGF- $\beta$ signaling by smad proteins. Adv. Immunol. 2000, $75,115-157$.

113. Moustakas, A.; Souchelnytskyi, S.; Heldin, C.H. Smad regulation in TGF- $\beta$ signal transduction. J. Cell Sci. 2001, 114, 4359-4369.

114. Mendjan, S.; Mascetti, V.L.; Ortmann, D.; Ortiz, M.; Karjosukarso, D.W.; Ng, Y.; Moreau, T.; Pedersen, R.A. Nanog and CDX2 pattern distinct subtypes of human mesoderm during exit from pluripotency. Cell Stem Cell 2014, 15, 310-325.

115. Muller, H.; Helin, K. The E2f transcription factors: Key regulators of cell proliferation. Biochim. Biophys. Acta 2000, 1470, M1-M12.

116. Ren, B.; Cam, H.; Takahashi, Y.; Volkert, T.; Terragni, J.; Young, R.A.; Dynlacht, B.D. E2f integrates cell cycle progression with DNA repair, replication, and $\mathrm{g}(2) / \mathrm{m}$ checkpoints. Genes Dev. 2002, 16, 245-256.

117. Wu, L.; Timmers, C.; Maiti, B.; Saavedra, H.I.; Sang, L.; Chong, G.T.; Nuckolls, F.; Giangrande, P.; Wright, F.A.; Field, S.J.; et al. The E2f1-3 transcription factors are essential for cellular proliferation. Nature 2001, 414, 457-462.

(C) 2015 by the authors; licensee MDPI, Basel, Switzerland. This article is an open access article distributed under the terms and conditions of the Creative Commons Attribution license (http://creativecommons.org/licenses/by/4.0/). 